\title{
Pengembangan Game Edukasi Pakaian Tradisional Indonesia Berbasis Android
}

\author{
Ardian Arifin $^{1}$, Ferry Marlianto ${ }^{2}$, Aris Budiman $^{3}$ \\ 1,2 Fakultas MIPA dan Teknologi IKIP PGRI Pontianak, Kalimantan Barat, \\ Jl Ampera Raya Pontianak ,Indonesia 78116 \\ ${ }^{3}$ Fakultas Komputer Akuntansi, Politeknik Putra Bangsa, Kalimantan Barat, \\ Jl Sultan Hamid II Pontianak, Indonesia 744187
}

\begin{abstract}
Culture in Indonesia has a lot of diversity. Indonesia which has many provinces also has many cultures. One of the cultures that exist in Indonesia is raditional clothing. Traditional clothing, a characteristic of adat and culture in each region and also used in each traditional ceremony. Along with the development of the times, the concern for the preservation of national culture, especially traditional clothing, was very minimal. For example, the lack of recognition and socialization of Indonesian culture in the community is one of the important factors why people's interest is lacking in traditonal clothing. This study aims to develop the development of an Android-based educational game on traditional Indonesian clothing. The method used in this study uses Research and Development methods. The results of this study were developed an educational game "Introduction to Traditional Clothing in Indonesia" on the Android platform that provides information to users about any traditional musical instruments in Indonesia. Educational games are expected to help in the introduction of existing cultures and can be used as a way to provide insight to children. From the results of testing carried out with the black box method, it can be concluded that this application can function well. And can provide users of Android smartphone games that are educational.
\end{abstract}

Keywords: Educational Games, Traditional Clothing, Android Smartphones

Abstrak - Budaya di Indonesia memiliki banyak keragaman. Indonesia yang memiliki banyak provinsi juga memiliki banyak budaya. Salah satu budaya yang ada di Indonesia adalah pakaian raditional.Pakaian traditional me,cirikan adat dan budaya di tiap daerah dan juga digunakan di tiap upacara adat. Seiring perkembangan zaman, kepedulian pelestarian kebudayaan nasional khususnya pakaian tradisional menjadi sangat minim. Sebagai contoh kurangnya pengenalan dan sosialisasi akan budaya Indonesia sendiri dimasyarakat merupakan salah satu faktor penting mengapa minat masyarakat menjadi kurang terhadap pakaian traditonal.Penelitian ini bertujuan untuk pengembangan adalah pengembangan game edukasi berbasis Android pakaian traditional Indonesia. Metode yang digunakan dalam penelitian ini menggunakan metode Penelitian dan Pengembangan (Reasearch and Development). hasil dari penelitian ini adalah dikembangkan sebuah game edukasi "Pengenalan Pakaian Tradisional di Indonesia" pada platform Android yang memberikan informasi kepada pengguna mengenai alat musik tradisional apa saja yang ada di Indonesia. Game edukasi diharapkan dapat membantu dalam pengenalan budaya yang ada dan dapat dijadikan sebagai untuk memberikan wawasan kepada anakanak. Dari hasil pengujian yang dilakukan dengan metode black box, dapat disimpulkan bahwa aplikasi ini dapat berfungsi baik. Dan dapat memberikan pengguna smartphone android game yang edukatif.

Kata kunci: Game Edukasi, Pakaian Tradisional, Smartphone Android

\section{Pendahuluan}

Beraneka ragam dan budaya di Indonesia, membuat tanah air ini memiliki berbagai macam pakaian tradisional atau adat yang tersebar di 33 provinsi diseluruh provinsi Indonesia. Karena keunikannya, pakaian adat antara daerah yang satu dengan lainnya memiliki keunikan tersendiri. Sebut saja batik, batik tidak hanya dikenal di tanah air namun cukup dikenal hampir di seluruh manca negara. Batik merupakan kebanggaan dan citra bangsa Indonesia. Keanekaragaman budaya di Indonesia merupakan sebuah kondisi perbedaan masing-masing budaya. Salah satu faktornya adalah keadaan antara letak satu wilayah dengan wilayah lainnya. Wilayah Indonesia dimana secara keseluruhan, negara ini terdiri dari pulau-pulau, dari Sabang hingga Merauke. Pola maupun kebiasaan sehari-hari masyarakat tidaklah sama di setiap wilayah di tanah air disebabkan perbedaan wilayah.

Game edukasi juga bisa diberikan kepada remaja agar lebih mengenal kebudayaan daerah yang dimiliki. Usia remaja merupakan usia di mana anak-anak mengalami masa sekolah. Anak-anak masa sekolah mengembangkan kemampuan melakukan permainan (game) dengan peraturan. Batasan usia remaja umum digunakan oleh para ahli adalah antara 12 hingga 21 tahun. 
Rentang waktu usia biasanya dibedakan atas tiga, yaitu 12-15 tahun sebagai masa remaja awal (Desmita, 2005: 195). Usia 12 tahun ke atas merupakan periode operasional. Pada periode operasional mulai mempertimbangkan kemungkinan-kemungkinan masa depan yang akan dihadapi, serta akan menjadi apa dirinya kelak. Dalam pemecahan masalah, mereka sudah lebih sistematis, mengembangkan hipotesis mengenai mengapa sesuatu terjadi dengan cara tertentu (Cook \& Cook, 2005: 19).

Pengguna Android di Indonesiatiap tahunnya mengalami peningkatan yang signifikan. Bahkan pengguna Android di Indonesia masuk posisi 5 pengguna aktif. Terhitung ada 47 juta, atau sekitar 14\% dari seluruh total pengguna ponsel (Heriyanto, 2014). Penggunaan game edukasi sebagai metode untuk pengenalan kebudayaaan untuk anak-anak dapat diimplementasikan dengan kolaborasi dari device Android dan media pembelajaran pengenalan kebudayaan Indonesia. Karena pengguna Android di kalangan siswa sangat tinggi, sehingga dengan menggunakan kolaborasi ini dapat digunakan untuk pengenalan kebudayaan Indonesia melalui device Android.

Berdasarkan latar belakang masalah yang telah dikemukakan, maka pokok permasalahan yang dihadapi adalah bagaimana merancang aplikasi game Edukasi pengenalan pakaian di Indonesia berbasis Android?

Metode yang digunakan dalam penelitian ini menggunakan metode Penelitian dan Pengembangan (Reasearch and Development). Metode Penelitan dan Pengembangan adalah metode yang digunakan untuk menghasilkan suatu produk perangkat lunak dan menguji kelayakan perangkat lunak yang dibangun. Menurut Sugiyono (2010), metode Penelitian dan Pengembangan adalah metode yang digunakan untuk menghasilkan produk tertentu dan menguji keefektifan produk tersebut.

Pada penelitian ini, peneliti membangun perangkat lunak dengan metode V-Model. Model ini merupakan perluasan dari model waterfall. Disebut sebagai perluasan karena tahap-tahapnya mirip dengan yang terdapat dalam model waterfall. Jika dalam model waterfall proses dijalankan secara linear, maka dalam model V proses dilakukan bercabang. Dalam model V ini digambarkan hubungan antara tahap pengembangan software dengan tahap pengujiannya.

\section{METODE}

Pengembangan aplikasi permainan Edukasi berbasis Android pada penelitian ini menggunakan metode pengembangan perangkat lunak V- Model, dengan urutan sebagai berikut :

1. Analisis Kebutuhan

Analisis kebutuhan merupakan proses pengumpulan informasi tentang kebutuhan-kebutuhan pengguna terhadap perangkat lunak yang akan dikembangkan. Informasi ini nantinya akan digunakan sebagai acauan untuk mengetahui fitur apa saja yang akan ada pada Game Edukasi Berbasis Android.

2. Analisis Spesifikasi

Analisis spesifikasi menjabarkan apa-apa saja yang harus dimiliki oleh sistem agar dapat berjalan. Analisis spesifikasi bertujuan untuk mengetahui sistem seperti apa yang cocok diterapkan, perangkat keras dan perangkat lunak apa saja yang dibutuhkan serta siapa saja pengguna yang akan menggunakan sistem ini.

3. Desain

a. Desain Game

Dalam sebuah pengembangan game, tahap desain game merupakan tahap perencanaan yang dilakukan oleh seorang pengembang untuk menentukan genre atau jenis game, cara bermain, tingkat kesukaran atau level game.

b. Desain Sistem dengan UML

Proses pengembangan selanjutnya adalah proses desain pengembangan perangkat lunak. Desain sistem perangkat lunak yang dibuat nantinya akan dijadikan sebagai acuan pengembang dalam penulisan kode. Desain sistem perangkat lunak ini harus sesuai karakteristik perangkat lunak yang akan dibuat serta mampu mempermudah dan memperjelas pengembang dalam proses pembuatan perangkat lunak. Penelitian ini menggunakan desain sistem model Unified Model Language (UML) dikarenakan model ini paling sesuai digunakan untuk mengembangkan sistem berorientasi objek.

\section{c. Desain Antar Muka}

Desain antar muka merupakan hal yang sangat penting dalam pengembangan perangkat lunak terutama dalam mengembangkan aplikasi permainan. User interface merupakan jembatan interaksi antara pengguna dengan sistem, selain itu desain tokoh dan karakter dalam permainan juga harus direncanakan dengan baik dan menarik. Sehingga penggguan akan merasa nyaman dan tertarik dalam bermain game. Desain antar muka juga harus mampu menggambarkan nilai atau kisah yang akan di sampaikan dalam bentuk permainan kepada pengguna.

4. Implementasi 
Desain yang telah dirancang kemudian ditranslasikan kedalam kode melalui event-event untuk mengimplementasikan logika program. Proses implementasi ini dilakukan pada perangkat lunak pengembangan.

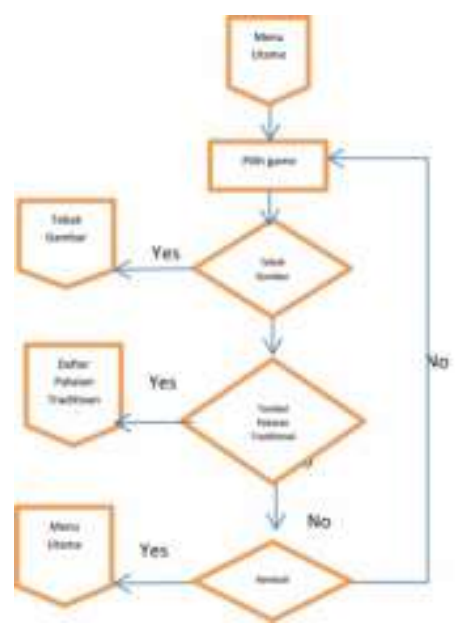

Gambar 1. Flowchart Proses Menu Game Edukasi PakaianTradisional

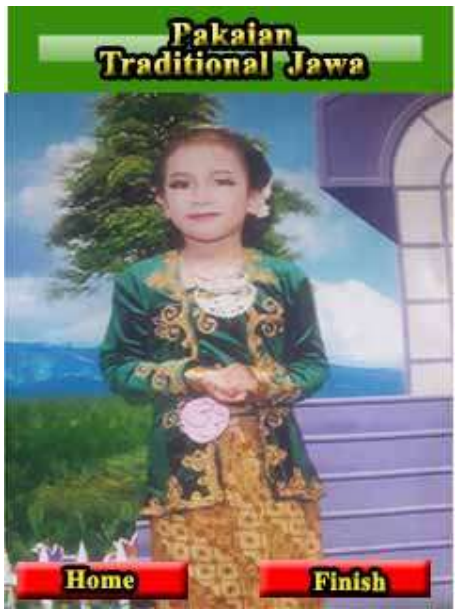

Gambar 4.10 . Pakaian Traditonal Jawa

Analisis kelayakan merupakan proses yang mempelajari atau menganalisa permasalahan yang telah ditentukan sesuai dengan tujuan akhir yang akan dicapai. Analisa kelayakan digunakan untuk menentukan kemungkinan keberhasilan solusi yang diusulkan. Tahapan ini berguna untuk memastikan bahwa solusi yang diusulkan tersebut benar-benar tercapai dengan sumber daya dan dengan memperhatikan kendala yang terdapat pada permasalahan serta dampak terhadap lingkungan sekeliling.

1. Kelayakan Sistem

Ada beberapa tipe dalam melakukan analisis kelayakan sistem yaitu kelayakan teknis, kelayakan ekonomi, kelayakan operasional. Ditinjau dari kelayakan teknis aplikasi ini telah layak karena teknologi untuk mendukung aplikasi ini merupakan teknologi yang mudah didapatkan, murah dan tingkat pemakainnya mudah.

2. Kelebihan sistem

Kelebihan dari aplikasi game edukasi ini adalah dapat mengasah ingatan tentang nama dan bentuk dari 
jenis-jenis Pakaian tradisional Indonesia. Selain itu, aplikasi game edukasi ini juga sebagai sarana pembelajaran untuk mengingat dan meningkatkan pengetahuan tentang jenis-jenis Pakaian tradisional Indonesia.

\section{Kelemahan sistem}

Sistem yang dibuat tidak menutup kemungkinan memiliki kelemahan pada saat implementasi atau digunakan oleh pengguna secara luas. Dari kelemahan sistem yang ada diharapkan untuk pengembangan selanjutnya dapat memperbaiki kelemahan tersebut. Dalam pembuatan aplikasi game edukasi ini, ada beberapa hambatan, antara lain:

a. Splash Screen dalam pembuatan aplikasi game edukasi tersebut tidak dapat diganti.

b. Beberapa sprite Pakaian nampak blur ketika dijalankan di beberapa gadget dengan resolusi yang lebih besar.

Dari beberapa hambatan di atas, ditemukan sebab dari permasalahan tersebut, yaitu dari aplikasi pembuat aplikasi game edukasi itu sendiri, dalam hal ini MIT karena dalam MIT dalam versi gratis memang tidak dapat mengganti splash screen. Kemudian sebagian sprite Pakaian yang nampak blur itu karena ukuran sprite yang dibuat sebelumnya berukuran lebih kecil.

Berdasarkan penyebab di atas, maka dilakukan pengeditan ulang sprite- sprite yang nampak blur sebelumnya ke ukuran yang lebih besar agar terlihat lebih jelas. Dari hasil update dan setelah dilakukan compile ulang, aplikasi sudah lebih baik dari sebelumnya.

\section{Pengujian}

Pengujian merupakan suatu keharusan dalam membuat aplikasi untuk mendapatkan informasi mengenai kualitas dari aplikasi yang telah dibuat dan mengetahui apakah fungsi - fungsi dari aplikasi tersebut telah berjalan sesuai dengan tujuan. Metode dari pengujian sistem dalam penelitian ini yaitu metode pengujian black box.

a. Hasil Pengujian

Berdasarkan rencana pengujian, maka dapat dilakukan pengujian sebagai berikut:

Tabel 2. Jenis Games

\begin{tabular}{|l|l|l|l|}
\hline \multicolumn{4}{|c|}{ Kasus Dan Hasil Uji } \\
\hline $\begin{array}{l}\text { Aksi/data } \\
\text { Masukan }\end{array}$ & Yang diharapkan & Pengamatan & Kesimpulan \\
\hline $\begin{array}{l}\text { Menekan Tombol } \\
\text { Tebak Gambar }\end{array}$ & $\begin{array}{l}\text { Berpindah ke } \\
\text { Scene Tebak } \\
\text { Gambar }\end{array}$ & $\begin{array}{l}\text { Pilihan aksi sesuai } \\
\text { yang diharapkan. }\end{array}$ & Berhasil \\
\hline $\begin{array}{l}\text { Menekan Tombol } \\
\text { Tebak Kata }\end{array}$ & $\begin{array}{l}\text { Berpindah ke } \\
\text { Scene Tebak Kata }\end{array}$ & $\begin{array}{l}\text { Pilihan aksi sesuai } \\
\text { yang diharapkan. }\end{array}$ & Berhasil \\
\hline $\begin{array}{l}\text { Menekan daftar } \\
\text { Pakaian } \\
\text { tradisional }\end{array}$ & $\begin{array}{l}\text { berpindah ke } \\
\text { scene daftar } \\
\text { Pakaian tradisional }\end{array}$ & $\begin{array}{l}\text { Pilihan aksi sesuai } \\
\text { yang diharapkan. }\end{array}$ & Berhasil \\
\hline $\begin{array}{l}\text { Menekan tombol } \\
\text { Kembali }\end{array}$ & $\begin{array}{l}\text { kembali ke scene } \\
\text { menu utama }\end{array}$ & $\begin{array}{l}\text { Pilihan aksi sesuai } \\
\text { yang diharapkan. }\end{array}$ & Berhasil \\
\hline
\end{tabular}

III.Pengujian Pada Menu Jawaban Game

Tabel 3. jawaban Games

Kasus Dan Hasil Uji 
Journal of Computer Networks, Architecture and High Performance Computing e-ISSN 2655-9102, Volume 1, No. 2, Januari 2019, pp 1-9

\begin{tabular}{|l|l|l|l|}
\hline $\begin{array}{l}\text { Aksi/data } \\
\text { masukan }\end{array}$ & Yang diharapkan & Pengamatan & Kesimpulan \\
\hline $\begin{array}{l}\text { Menekan tombol } \\
\text { pilihan jawaban }\end{array}$ & $\begin{array}{l}\text { Jika jawaban benar } \\
\text { skor bertambah, }\end{array}$ & $\begin{array}{l}\text { Pilihan aksi sesuai } \\
\text { yang diharapkan. }\end{array}$ & Berhasil \\
\hline $\begin{array}{l}\text { Menekan tombol } \\
\text { Back pada Android }\end{array}$ & $\begin{array}{l}\text { Muncul Popup } \\
\text { Pause dan Game } \\
\text { berhenti sementara }\end{array}$ & $\begin{array}{l}\text { Pilihan aksi sesuai } \\
\text { yang diharapkan. }\end{array}$ & Berhasil \\
\hline
\end{tabular}

Aplikasi Game pakaian traditional Indonesia ini telah dikembangkan sesuai dengan pedoman System Development Life Cycle. Tahapan-tahapan yang sudah dilalui yaitu analisis kebutuhan, analisis spesifikasi, desain, dan implementasi. Setelah perangkat lunak jadi, peneliti melakukan pengujian dalam rangka melakukan proses verifikasi dan validasi. Adapun proses verifikasi dengan melakukan pengujian unit dengan menggunakan metode whitebox dan pengujian integrasi dengan menggunakan metode blackbox. Sedangkan proses validasi yaitu dengan melakukan pengujian sistem dengan menggunakan metode stress test dan instability test, kemudian untuk pengujian acceptance test dengan menggunakan metode expert review dan playability test.

\section{A.Kesimpulan}

Berdasarkan implementasi dan hasil pengujian yang telah dilakukan dapat disimpulkan bahwa aplikasi ini berjalan baik sesuai dengan fungsinya. Aplikasi ini berjalan pada smartphone berbasis Android yang pada dasarnya merupakan game edukasi yang diharapkan mampu menambah pengetahuan khususnya anak-anak dan remaja dalam memperkenalkan Pakaian tradisional. Game edukasi ini bukan hanya sekadar untuk mencari kesenangan, tapi juga untuk bisa bermain sambil belajar karena didalamnya terdapat konten media yang bermanfaat yaitu mengenai pengenalan Pakaian tradisional. Aplikasi ini memiliki kekurangan yaitu dari banyaknya Pakaian tradisional yang ada di Indonesia, pembuat hanya mengambil beberapa Pakaian tradisional yang ada di Indonesia untuk dimasukkan ke dalam game.

\section{DAFTAR PUSTAKA}

Jurnal /Artikel

[1]Heriyanto, T. (2014). detikinet. Retrieved February 28, 2014, from detik: http://inet.detik.com/read/2014/02/03/171002/2485920/317/indonesia- masuk-5-besar-negarapengguna-smartphone

[2]Skalanews. (2012). Kemdikbud Baru Mencatat 67.273 Warisan Budaya Indonesia. Dipetik 15 Februari 2016, dari skalanews.com: http://skalanews.com/news/detail/128316/2/kemdikbud-baru-mencatat- 67.273-warisan-budayaindonesia-.html

[3]Kramer, W. (2000). What is a Game ? Retrieved April 31, 2014, from The Games Journal: http://www.the gamesjournal.com/articles/WhatIsaGame.shtml

[4]Malone, T. W., \& Lepper, M. R. (1987). Making Learning Fun: A Taxonomy of Intrinsic Motivations for Learning. Aptitude, Learning, and Instruction Volume 3: Conative and Affective Process Analyses.

Monograph, edited book, book

[5]Cook, J. L., \& Cook, G. (2005). Child Development : Principles \& Perspectives. Allyn and Bacon. [6]Departemen Agama . Mushaf Al-Quran Terjemah. Depok: 2002.

[7]Desmita. (2005). Psikologi Perkembangan. Bandung: Remaja Rosdakarya. Ensiklopedi National Indonesia.1990. Jilid 11, cetakan pertama. Jakarta: PT.Cipta Adi Pustaka

[8]Granic, I., Lobel, A., \& Engels, C. R. (2014). The Benefits of Playing Video Games. American Psychologist.

[9]Griffiths, M. (2002). The educational benefits of video games. Education and Health.

[10[Sedyawati. 1992. Sejarah Kebudayaan Indonesia: Seni Pertunjukan dan Seni Media. Jakarta: RajaGrafindo Persada. 
[11]Sudono, A. (2000). Sumber belajar dan alat permainan untuk pendidikan anak usia dini. Grasindo.

[12]Sadiman, A. (2011). Media Pendidikan: Pengertian, Pengembangan, dan Pemanfaatannya. Jakarta: Pustekom Depdikbud dan CV Rajawali.

[13]Safaat,Nazarudin. 2012.PemogramanAplikasi Mobile Smartphone dan Tablet PC Berbasis Android. Informatika: Bandung.

\section{Theses, Dissertation}

[14]Ahsan. 2015. Game Pengenalan Makanan Khas Sulawesi Selatan Berbasis Android. Skripsi. Makassar: UIN Alauddin Makassar.

[15]Mirza. 2014. Analisis Pengembangan Game Edukasi "Indonesiaku" Sebagai Pengenalan Warisan Budaya Indonesia untuk Anak Usia 12-15 Tahun. Skripsi. Yogyakarta. Universitas negeri Yogyakarta.

[17]Rizko. 2012. Rancang Bangun Aplikasi Game untuk Mengenal Tokoh Kemerdekaan Berbasis Desktop. Skripsi. Makassar: UIN Alauddin Makassar.

[18]Willoughby, T., Adachi, P. J., \& Good, M. (2011). A Longitudinal Study of the Association Between Violent Video Game Play and Aggression Among Adolescents. Developmental Psychology. Retrieved February 14, 2016, from Berita Satu

[19]Virvou, M., Katsionis, G., \& Manos, K. (2005). Combining Software Games with Education: Evaluation of its Educational. Educational Technology \& Society.

[20]Felicia, P. (2011, March). What evidence is there that digital games can be better than tradisional methods to motivate and teach students? Retrieved May 2014,19,fromhttp://linked.eun.org/c/document_library/get_file?p_1_id=17135\&folderId $=23949 \&$ name $=$ DLFE-750.pdf

Papers and Industrial Reports

[21]AppBrain. 2014. Most Popular Google Play Categories. Retrieved March 25, 2014, from AppBrain: http://www.appbrain.com/stats/android-market-app- categories

[22]Manar, G. (2012). Budaya, Elemen Penting Pembangunan Sebuah Bangsa. Retrieved February 6, 2014, from http://www.undip.ac.id/index.php?option=com_content\&view=article\&id $=2541$ :budaya-elemen-penting-pembangunan-sebuah-bangsa- $\&$ catid=78:latestnews\&Itemid $=1092$.

[23] Salim dan Salim. 1991. Dikutip 12 Mare 2016 dari googleweblight.com/lite url=http://cara.pro/pengertian-fungsi-jenis- contoh-musik-nusantara-.html

[24] Tumbijo. $1977 . \quad$ Dikutip $12 \quad$ Maret 2016 dari googleweblight.com/lite url=http://cara.pro/pengertian-fungsi-jenis- contoh-musik-nusantara-.html 